\title{
Research on Quantitative Model of Risk Assessment for Amusement Rides
}

\author{
Yuan Xiao ${ }^{1, \text { a }}$, Jianping Ye $\mathrm{e}^{1, \mathrm{~b}}$, Ruomeng $\mathrm{Chen}^{1}$, Minglang Tang ${ }^{2}$ \\ ${ }^{1}$ China Special Equipment Inspection and Research Institute, Beijing, China \\ ${ }^{2}$ Guangxi Construction Machinery Manufacturing Co., Ltd, Nanning, China \\ axyduong@163.com, bjycn@sina.com
}

Keywords: quantitative model; risk assessment; amusement ride; correction factor

\begin{abstract}
According to the features of amusement rides and the definition, the quantitative model of risk assessment for amusement rides was build based on hazard probability and hazardous consequence calculated with economical loss. According to the structure features that the amusement rides are composed with mechanical, electric control, hydraulic and other systems, the failure probability of electric control system was calculated with unit failure probability and simplified bathtub curve; and the failure probability of mechanical system is calculated according to the fatigue damage accumulation theory. The hazard probability is modified by comprehensive correction factor to consider the influence on the risk performance of amusement rides caused by the safety measures, redundancy units, strengthening process and management methods. The loss rate, direct economic loss and indirect economic loss are used to calculate the quantitative hazardous consequence. The steps of risk assessment based on the quantitative model were introduced.
\end{abstract}

\section{Introduction}

So far, the general inspecting methods are still used to inspect all amusement rides without adjusting the hierarchy and emphasis to adapt to the different the characteristics of different amusement rides. Therefore, the potential risks cannot be inspected in some amusement rides. Once the accident occurs, the economic and social losses will suffer severe consequence. Therefore, the risks of running amusement rides are to be assessed, and taken valid measures to prevent the accidents [1].

There are some successful models and measures used to assess the risks of special equipments, but they are very rough and non-quantitative. The available models and measures are not fit for the amusement rides with the development of amusement rides, and the weaknesses becomes more and more outstanding. The weaknesses mainly focus on the probability of faults, effective degree of accidents, non-restricted accidents and so on.

\section{Risk analysis models}

Risk assessment. The various risks exist along the life cycles of amusement rides. The define of risk is: A probability or threat of a damage, injury, liability, loss, or other negative occurrence that is caused by external or internal vulnerabilities, and that may be neutralized through preemptive action. According to European Machine Safety Standards, the risk assessment is: The identification, evaluation, and estimation of the levels of risks involved in a situation, their comparison against benchmarks or standards, and determination of an acceptable level of risk.

There are many risk assessment models and methods. The most common are: Risk Rank (RR), Preliminary Hazard Analysis (PHA), Failure Mode and Effects Analysis (FMEA), Fault Tree Analysis (FTA), Risk Matrix and so on [2]. The above models and methods are qualitative, and can not obtain quantitative results.

Quantitative model of risk assessment for amusement rides. The risk of amusement ride is the probable loss under the certain hazards. Therefore, the risk of amusement ride is determined by 
four factors: occurrence probability of hazards, hazard influence, influence range and value of equipment, and hazard bearing performance.

The quantitative model is to be build to obtain the quantitative risk of amusement ride. The risk is the function of probability and damage degree according to the definition of risk [2-5], expressed as:

$$
R=f(P, S)=\sum_{i=1}^{n} P\left(H_{i}\right) \bullet S_{i}
$$

Where $\mathrm{R}$ is risk, $P\left(H_{i}\right)$ is the hazard probability of the ith hazard, and $S_{i}$ is the hazard rank. The hazard consequence is related to the hazard bearing performance and the value of equipment. Therefore, $S_{i}$ is expressed as:

$$
S_{i}=\sum_{j=1}^{n} V_{i j} E_{i j}
$$

Where $\mathrm{n}$ is the number of devices which bear hazards, $V_{i j}$ is the hazard bearing performance of jth device, $E_{i j}$ is the economic loss of jth device. $E_{i j}$ is composed of direct loss $E_{d}$ and indirect loss $E_{i}$. Therefore, the comprehensive risk model is as follow.

$$
R=f(P, S)=\sum_{i=1}^{n} P\left(H_{i}\right) \bullet S_{i}=\sum_{i=1}^{n} P\left(H_{i}\right) \bullet \sum_{j=1}^{n} V\left(S_{i j} \mid H_{i}\right)\left(E_{d}+E_{i}\right)
$$

Where, $V\left(S_{i j} \mid H_{i}\right)$ reflects the hazard strength and bearing performance. Therefore, the above model reflects the four influence factors, and is calculated with qualitative method. To calculate the quantitative value of risk, the hazard bearing performance is replaced by hazard probability multiplied by modify factors.

\section{Calculation method of quantitative model of risk assessment}

Calculation of hazard probability. The amusement ride is composed of mechanical system, hydraulic system, electronic control system and other system. If the system is different, the calculation method of hazard probability is different.

a)Electronic control system. The failure probability of control unit can be obtained according to the failure probability of component, so does the failure probability of electronic control system [6]. The general failure rate of control unit is calculated with follow model.

$$
\lambda_{i}=\sum_{j=1}^{n} N_{i}\left(\lambda_{Q} \pi_{Q}\right)
$$

Where, $N_{i}$ is the number of ith component, $\lambda_{Q}$ is the failure rate, and $\pi_{Q}$ is the quality coefficient. The failure rate and quality coefficient can be obtained from the database. Beside the failure rate and quality coefficient, the failure probability is related to the working time length, shown as Fig.1. The Fig. 1 is called bathtub curve. In order to use the bathtub curve in engineering, the bathtub curve usually is simplified with linear, shown as Fig. 2 [7].

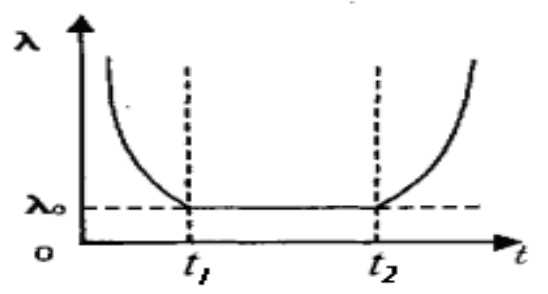

Fig.1 Failure curve

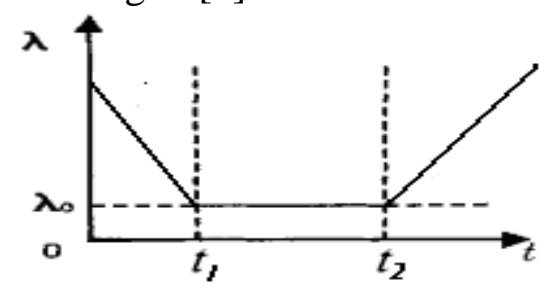

Fig.2 Simplified failure rate curve

The exponential distribution is usually used as the life distribution of electronic control system. According to life distribution, the reliability and failure rate can be obtained. Therefore, the hazard probability of electronic control system can also be obtained [8]. 


$$
\begin{aligned}
& R(t)=e^{-\lambda t} \\
& P(H)=F(t)=1-e^{-\lambda t}
\end{aligned}
$$

b)Hydraulic system. The failure rate of hydraulic system is:

$$
\lambda=\sum_{i=1}^{n} \lambda_{i} t
$$

The life distribution of hydraulic unit also uses exponential distribution, and the hazard probability of hydraulic system can also be obtained same as (7).

c)Mechanical system. Most failures of mechanical system are caused by component fatigue failure bearing varying stress. The fatigue failure is a process of fatigue damage accumulation [9]. Therefore, the hazard probability of mechanical system can be obtained with damage rate.

$$
P(H)=K \sum \frac{n_{i}}{N}
$$

Where, $K$ is correction coefficient, $N$ is the total operating times in the design life-span, and $n_{i}$ is the operating times at ith operating. The longer is the operating time, and the more is operating times, the higher is the hazard probability. When the $P(H)$ is equal to 1 , the equipment occurs failure.

Correction of hazard probability. Some redundant units and safe protection measures are used to promote the safety when designers design amusement rides. The advanced processes and inspection devices are used to improve the quality when the amusement rides are manufactured [10]. Therefore, the hazard bearing performance can be improved. The reasonable operating manage measures such as reasonable operating procedures, safety operating manual, safe inspection ahead of operating, reasonable emergency measures, can decrease the operating hazard. Considering all above strengthening and manage measures, the hazard probability is corrected by correction factor as follow.

$$
K=k_{e} k_{m}
$$

Where, $k_{e}$ is equipment factor which is related to redundant units and safe protection measures, $k_{m}$ is manage factor which is related to operating, maintain, inspection and managing measures.

Consequence of hazard. The loss severity of amusement ride is the loss value caused by an accident, includes direct loss $E_{d}$ and indirect loss $E_{i}$. According to the National Standard GB6721-1986, direct loss $E_{d}$ includes salary paid for removing accidents, costs of equipment repair and compensation for visitors and so on. Indirect loss $E_{i}$ includes losses of shutdown, yield reduction, resource, and environment, and so on. The National Standard describes the calculating method for direct loss, but not for indirect loss. To obtain the indirect loss, the harm severe rate and equipment value were used, shown as follow.

$$
E_{i}=V_{i} \times \frac{D_{L}}{D} \times 10^{6}
$$
time.

Where, $V_{i}$ is the device value, $D_{L}$ is the loss operating time and $D$ is the total operating

\section{Steps of risk assessment for amusement rides}

The steps of risk assessment for amusement rides with quantitative model are as follow.

Step1: According to the characters, identify various hazards, hazard status and hazard accident, and obtain risk factors of amusement ride.

Step2: According to risk factors of amusement ride, identify the risk device components and calculate the hazard probability of different system with (6), (8). 
Step3: According to redundant units, safe protection measures and managing characteristics, determine the equipment correction factor and managing correction factor, and then calculate the comprehensive correction factor.

Step4: According to the National Standard, calculate the direct loss. Determine the loss working hour based on the hazard severe and calculate the indirect loss with (10). Therefore, the hazard consequence can be calculated with (4).

Step5: Calculate the quantitative risk of amusement ride with (3).

\section{Conclusions}

At present, the risk states of amusement rides are determined by inspectors after regular inspecting, and the inspectors also determine the equipments are whether qualified or not. With the qualitative method, the obtained results are subjective and one-sidedness. For system and operating state of amusement ride, the quantitative risk result can be obtained with the quantitative model. Therefore, the artificial errors and one-sidedness are avoided. Comparing with other qualitative risk assessment methods such as risk matrix, the rough shortcoming is also avoided. The risk quantitative model includes each link of amusement ride life cycle. Therefore, the risk assessment result reflects the operating risk degree accurately.

\section{Acknowledgment}

This work was sponsored by the "National Twentieth Five-Year Key Technology Supported Program of Ministry of Science and Technology P.R.C."; under contract "Research on Key Technologies of Accident Presentation for Special Equipments Based on Risk Technologies" (contract number 2011BAK06B05).

\section{References}

[1] J. Liang and G. H. Chen: Discussion on Establishment of Special Equipment Risk Management System and Its Key Issues, China Safety Science Journal, Vol. 20(2010), pp.132-138(in Chinese).

[2] Y. Wu, D.S. Liu, X. Lu and Q.H. Song: A Quantitative Assessment Model for Property Risk Caused by Single Landslide, Rock and Soil Mechanics, Vol. 31(2010), pp.342-348(in Chinese).

[3] J. B. Nicholas: System Safety Engineering and Risk Assessment, Washington, D. C.: Taylor \& Francis (1990).

[4] American Petroleum Institute: Risk-based Inspection Base Resource Document, API 581(2008).

[5] American Petroleum Institute: Risk-based Inspection-Recommended Practice, API 580(2002).

[6] F.W. Sun: Reliability Mathematics Model and Application of the Programmable Controller System, Mathematica Applicata, Vol. 15(2002): 68-71(in Chinese)

[7] J. Moubray, Reliability-Centered Maintenance (2nd Edition), New York: Industrial Press (1997).

[8] E.R. Hnatek, Practical Reliability of Electronic Equipment and Products, Washington, D. C.: Taylor \& Francis (2002).

[9] M.A. Miner, Cumulative Damage in Fatigue, Journal of Applied Mechanics, Vol. 12(1945):159-164.

[10]G. Chen, S.Z. Zuo, X.R. Tao, G.D. Jia, R.Y. He and L. Sun, The Risk Assessment Technology for Pressure-containing Equipment and it's Application and Developing Trend in China, Journal of Safety Science and Technology, Vol. 1(2005):31-35(in Chinese). 